\title{
Imigração internacional no Brasil, os novos fluxos: um estudo de caso da
} imigração de portugueses - os investidores individuais ${ }^{1}$

\author{
Prof.‥ Natália Dias Andrade de Faria² \\ Prof. Duval Fernandes ${ }^{3}$
}

No período que se segue à crise econômica de 2008, o Brasil passou a receber importante número de imigrantes internacionais dos países do hemisfério Norte, que tinham em particular, um nível de instrução elevado em relação à média da população brasileira. $O$ caso dos portugueses tinha especial relevância, pois além de chegar ao Brasil profissionais liberais, jovens, com alguma experiência no mercado europeu, parcela desses imigrantes vieram ao país com a intensão de abrir um negócio ou investir em alguma atividade já existente. Segundo os dados da Coordenação Geral de Imigração - CGlg, do Ministério do Trabalho, no período de 2011 a 2014 os portugueses estiveram sempre entre os 4 países cujos imigrantes mais demandaram autorização de residência no Brasil, ao amparo da Resolução Normativa ํo 84 de 2009, que disciplina a concessão de autorização para fins de obtenção de visto permanente para investidor estrangeiro individual, pessoa física. No período em estudo a entrada de portugueses investidores, utilizando da RN 84, foram: 192 em 2011, $283 \mathrm{em}$ 2012, 281 em 2013 e 149 em 2014. Ao mesmo tempo, o somatório dos valores de investimentos propostos pelos portugueses, também sempre esteve entre os 4 mais expressivos dentre os estrangeiros. Destaca-se em 2012 como o pais de maior investimento de pessoa física totalizando $\mathrm{R} \$ 77.791 .621,33$. Os estados que mais receberam estes portugueses concentram-se nas regiões Nordeste (nos Estados do Ceará, Pernambuco e Rio Grande do Norte) e Sudeste (em São Paulo e Rio de Janeiro), portanto esse trabalho tem por objetivo demostrar quantitativamente estes investimentos, especializando e analisando as solicitações de visto realizadas através da RN 84/2009.

\footnotetext{
${ }^{1}$ Trabalho apresentado no IX Encontro Nacional Sobre Migrações da ABEP. Campinas. Outubro 2015.

2 Mestranda do Programa em Geografia da PUC Minas contato: nandrade2705@yahoo.com.br

${ }^{3}$ Professor do Programa de Pós-Graduação em Geografia da PUC Minas, Coordenador do GEDEP/PUC Minas contato: $\underline{\text { duval@pucminas.br }}$
} 


\section{Introdução}

É entendido que as migrações impactam diretamente na dinâmica econômica e social das localidades tanto que recebem, quanto as que doam estes indivíduos. Políticas públicas são imprescindíveis para traçar estratégias de atendimento e regulamentação destes imigrantes. Por outro lado, "as migrações organizam-se cada vez mais através de redes informais que transcendem as fronteiras dos governos, não obstante e rigoroso controle fronteiriços e as leis restritivas, estão a perder a capacidade de controle" (CASTLES, 2005).

Diante da dualidade: políticas públicas de migração e a realidade das localidades que recebem estes migrantes, este estudo pretendeu verificar como a legislação tem sido utilizada para a obtenção de vistos e a efetividade da política voltada para o investimento produtivo nas regiões pesquisadas. Assim utilizou-se como instrumento de análise a Resolução Normativa no 84 de 2009 que "disciplina a concessão de autorização para fins de obtenção de visto permanente para investidor estrangeiro individual, pessoa física". Buscando levantar os impactos sociais e econômicos advindos destes investimentos, que segundo a legislação vigente deve ser de no mínimo $\mathrm{R} \$ 150.000,00$ (cento e cinquenta mil reais) para que o estrangeiro tenha o visto permanente de 5 anos. Indica a Resolução que para a concessão da autorização deverá ser considerado o interesse social do empreendimento "Na apreciação do pedido, será examinado prioritariamente o interesse social, caracterizado pela geração de emprego e renda no Brasil, pelo aumento de produtividade, pela assimilação de tecnologia e pela captação de recursos para setores específicos. "(artigo $2^{\circ}$, parágrafo $2^{\circ}, \mathrm{RN} \mathrm{n}^{\circ} \stackrel{84 \text { ) }}{ }$

Ao se considerar uma visão geral dos vistos recebidos pelos portugueses que tinham contrato de trabalho no Brasil, os resultados preliminares da REMIGR ${ }^{4}$ indicam que:

\footnotetext{
4 Pesquisa "Regresso para o futuro: a nova emigração e a relação com a sociedade portuguesa", desenvolvida pela Universidade de Lisboa, Universidade de Coimbra e Instituto Universitário de Lisboa ISCTE
} 
A profissão para cujo exercício mais vistos foram pedidos em todos estes anos foi a de administrador (entre 18\% dos pedidos em 2008 e $8 \%$ em 2013), estando as funções de direção e de gestão também muito presentes na lista das mais pretendidas por estes emigrantes.

Entre as profissões que mais portugueses atraíram entre 2008 e 2013 há várias de natureza técnica (como mecânico de aviões ou engenheiro geofísico), a par dos "músicos, intérpretes e instrumentistas", que na maioria dos anos em análise estão entre o grupo com mais vistos.

Ao se tratar especificamente daqueles que solicitaram autorização de permanência ao amparo da RN № 84, entre 2010 e 2014 o número de estrangeiros solicitante desse tipo de autorização aumentou 19,8\%, passando de 848 e 2010 a 1016 em 2014, tendo atingido um pico em 2013 com 1.174 solicitações. No mesmo período as solicitações apresentadas por cidadãos portugueses aumentou em 63,7\%, passando de 91 solicitações em 2010 para 149 em 2014. Em 2013 o número dessas demandas foi de 283, representando $24,2 \%$ de todos os pedidos apresentados ao amparo da RN em análise.

Assim tem-se como objetivo geral deste artigo $^{5}$ apresentar algumas características dos portugueses que solicitaram autorização de permanência no Brasil, entre os anos de 2010 e 2014, considerando os registros os dados da Coordenação Nacional de Migração (CGlg) e do Conselho Nacional de Imigração -CNlg divulgados em seus relatórios anuais e em tabulações especiais e de resultados preliminares da pesquisa REMIGR.

\section{Espacialização dos imigrantes no país e seus investimentos}

De acordo as informações disponibilizadas pela CGlg e pelo CNIg, no Brasil 937 portugueses que tiveram seus vistos emitidos, durante os anos de 2010 a 2014, utilizando da prerrogativa de investimento individual (pessoa física) ao amparo

\footnotetext{
${ }^{5}$ Esse artigo foi elaborado a partir de resultados preliminares da pesquisa "Imigração internacional no Brasil, os novos fluxos: um estudo de caso da imigração de portugueses - permanência, circularidade e trânsito" (Projeto CNPq 409344/2013-3)
} 
da RN n84/2009. Esta quantidade distribui-se entre os Estados brasileiros conforme representado no mapa 1.

\section{Mapa 1: PORTUGUESES INVESTIDORES NO BRASIL}

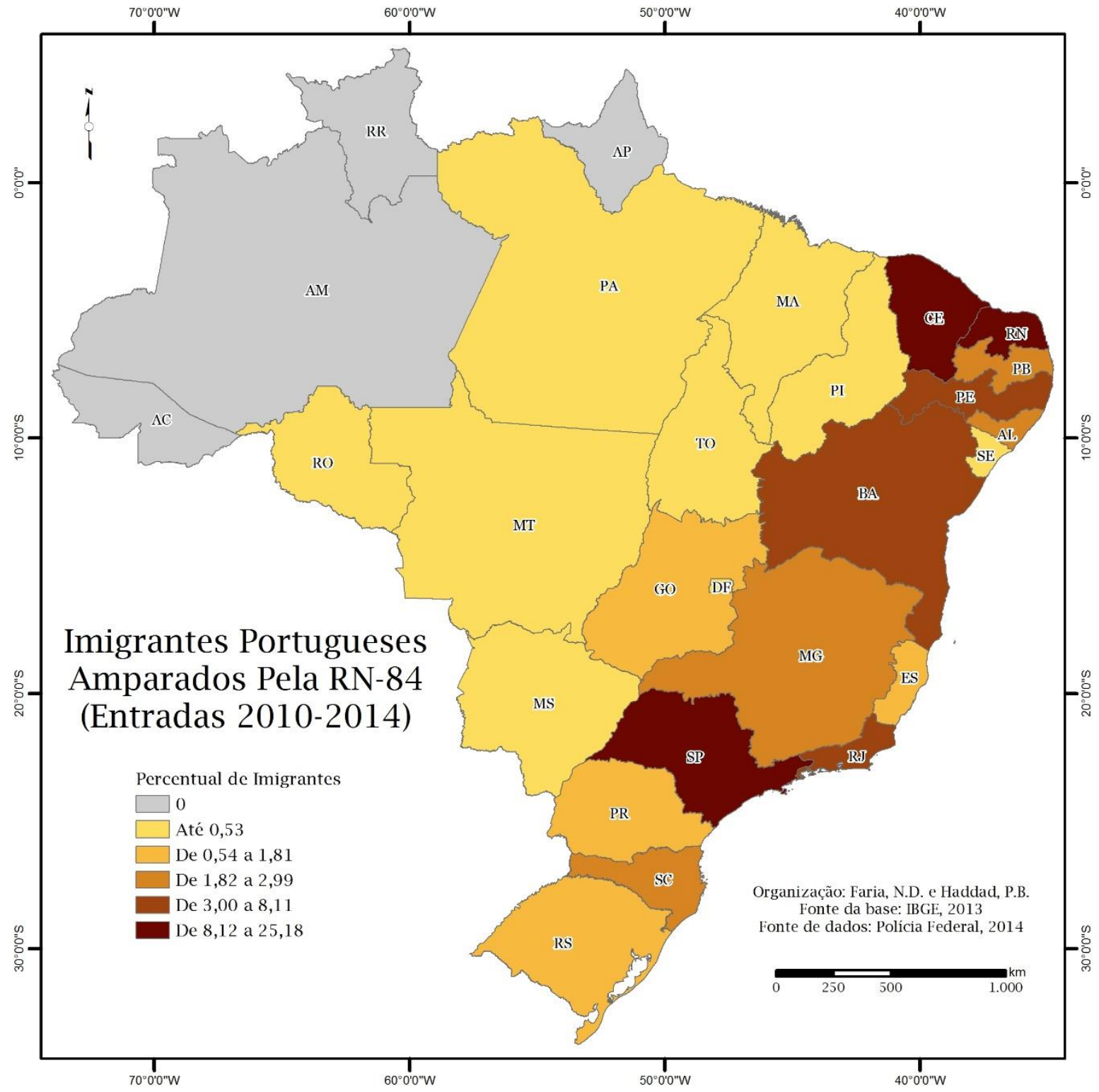

É possível observar, que os estados do Acre (AC), Amazonas (AM), Roraima (RR) e Amapá (AP) não receberam nenhum desses investidores nos últimos 4 anos, em contrapartida têm-se os estados do Ceará (CE), Rio Grande do Norte (RN) e São Paulo (SP), como os estados que mais recebem este perfil de imigrante. A maioria dos estados, 13 deles, recebem menos de $1 \%$ destes 
investidores, são estes estados: Piauí (PI), Maranhão (MA), Pará (PA), Tocantins (TO), Mato Grosso (MT), Rondônia (RO), Mato Grosso do Sul (MS), Goiás (GO), Paraná (PR), Rio Grande do Sul (RS), Distrito Federal (DF), Espirito Santo (ES) e Sergipe (SE). Em escalas intermediárias, os estados que recebem entre 1,8\% a $8 \%$, tem-se 7 estados (Santa Catarina (SC), Minas Gerais (MG), Rio de Janeiro (RJ), Bahia (BA), Paraíba (PB), Pernambuco (PE) e Alagoas (AL).

A representação dos investidores, também é possível ser analisada através do Gráfico 1 :

Gráfico 1: PORTUGUESES NO BRASIL

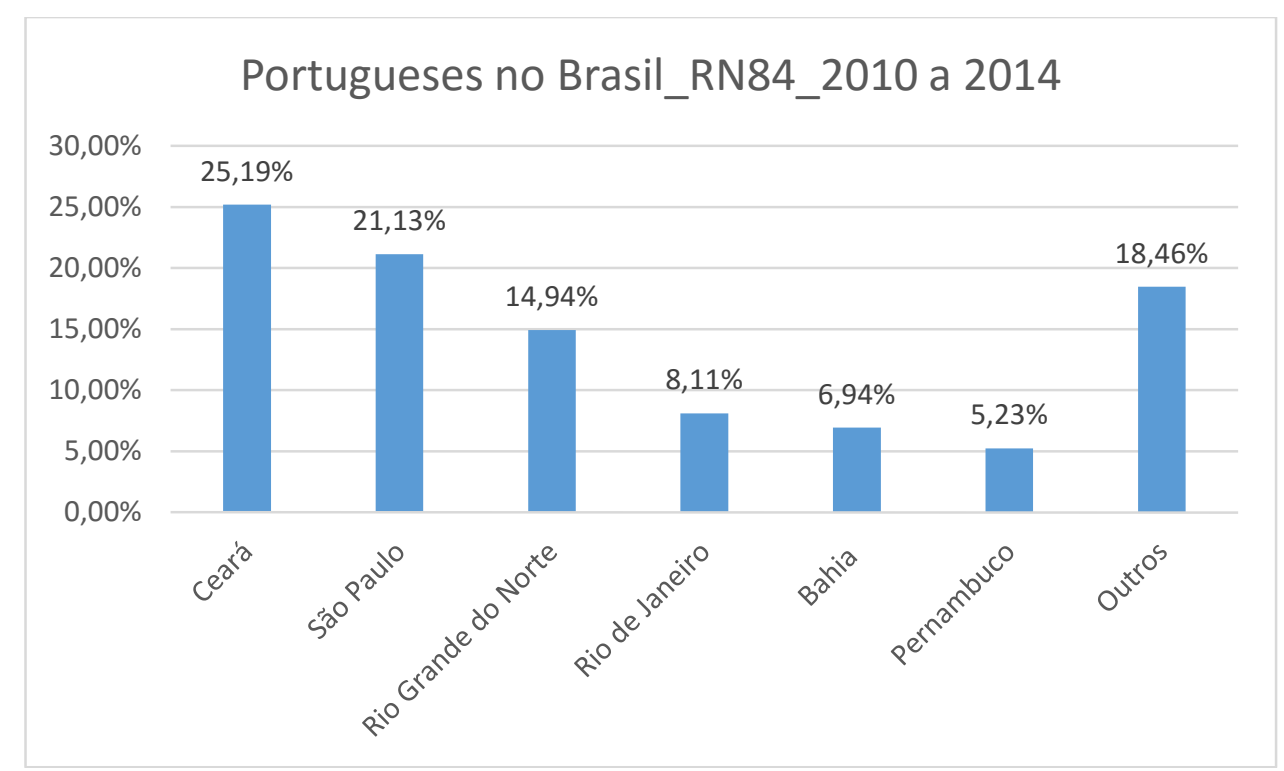

Fonte: CNIg, 2015

Observa-se que Ceará tem recebido a maior quantidade portugueses investidores $25,19 \%$, mais de um quarto do total, seguido por São Paulo $21,13 \%$, tendo uma expressiva diferença com o terceiro Estado, Rio Grande do Norte com 14,94\%. Percebe-se que os Estados do Sudeste e Nordeste são os que mais recebem estes portugueses, pois $81,54 \%$ dos portugueses concentram-se nos estados de Ceará, São Paulo, Rio Grande do Norte, Rio de Janeiro, Bahia e Pernambuco. Todos os demais Estados do país, conjuntamente recebem $18,45 \%$ dos investidores. 
Para solicitação da autorização de residência, o estrangeiro de informar no seu plano de negócios qual valor será investido, entre os anos de estudo (2010 a 2014) o total empreendido pelos Portugueses no Brasil foi de $R \$ 222.166 .478,48$, sendo o investimento por Estado distribuído de acordo com o gráfico 2.

\section{Gráfico 2: VALORES INVESTIDOS POR ESTADO}

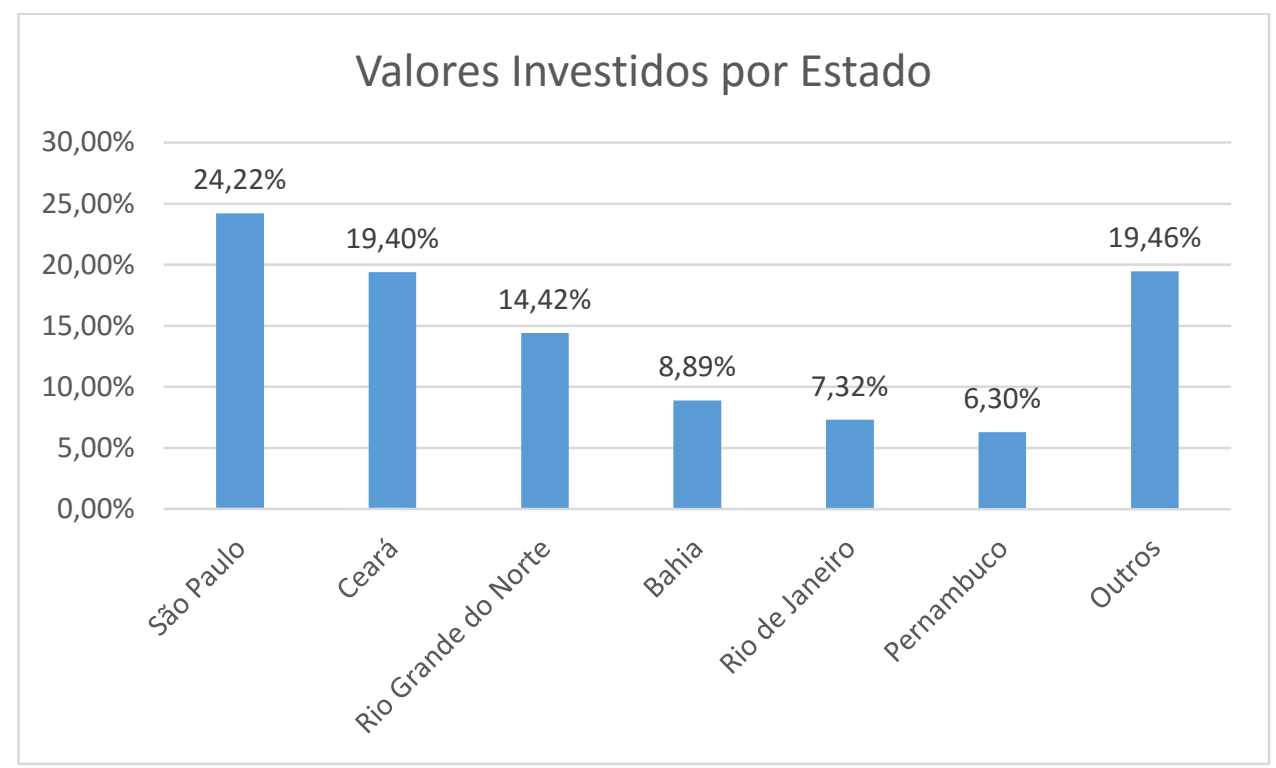

Fonte: CNIg, 2015

Mesmo tendo o Ceara como o principal Estado recebedor dos portugueses, quando se trata dos valores investidos, São Paulo recebe a maior porcentagem $24,22 \%$, o que equivale a $R \$ 53.798 .220,76$, enquanto Ceará recebe $19,40 \%$ ( $R \$$ 43.105.917,77). Seguido do Rio Grande do Norte recebendo $\mathrm{R} \$ 32.039 .421,60$ $(14,42 \%$ do total). Todos os demais Estados recebem menos de $10 \%$ dos investimentos portugueses.

O Ceará é uma exceção, o que deverá estar relacionado com a tendência, que surgia na transição do século, para a compra de segundas habitações junto à praia, em Fortaleza e áreas próximas. Os estados de São Paulo, Santa Catarina, Paraná, Rio de Janeiro e Ceará destacam-se (por esta ordem) por apresentarem os maiores níveis de pedidos de vista por naturais de Portugal com graus de licenciatura ou superiores. Estes são sobretudo estados das regiões com economias mais ricas (PESQUISA REMIGR, 2015)

Quando especializado estes investimentos, dentro dos Estados, tem-se 0 observado no Mapa 2. 


\section{Mapa 2: VALORES INVESTIDOS PELO PORTUGUESES NOS ESTADOS}

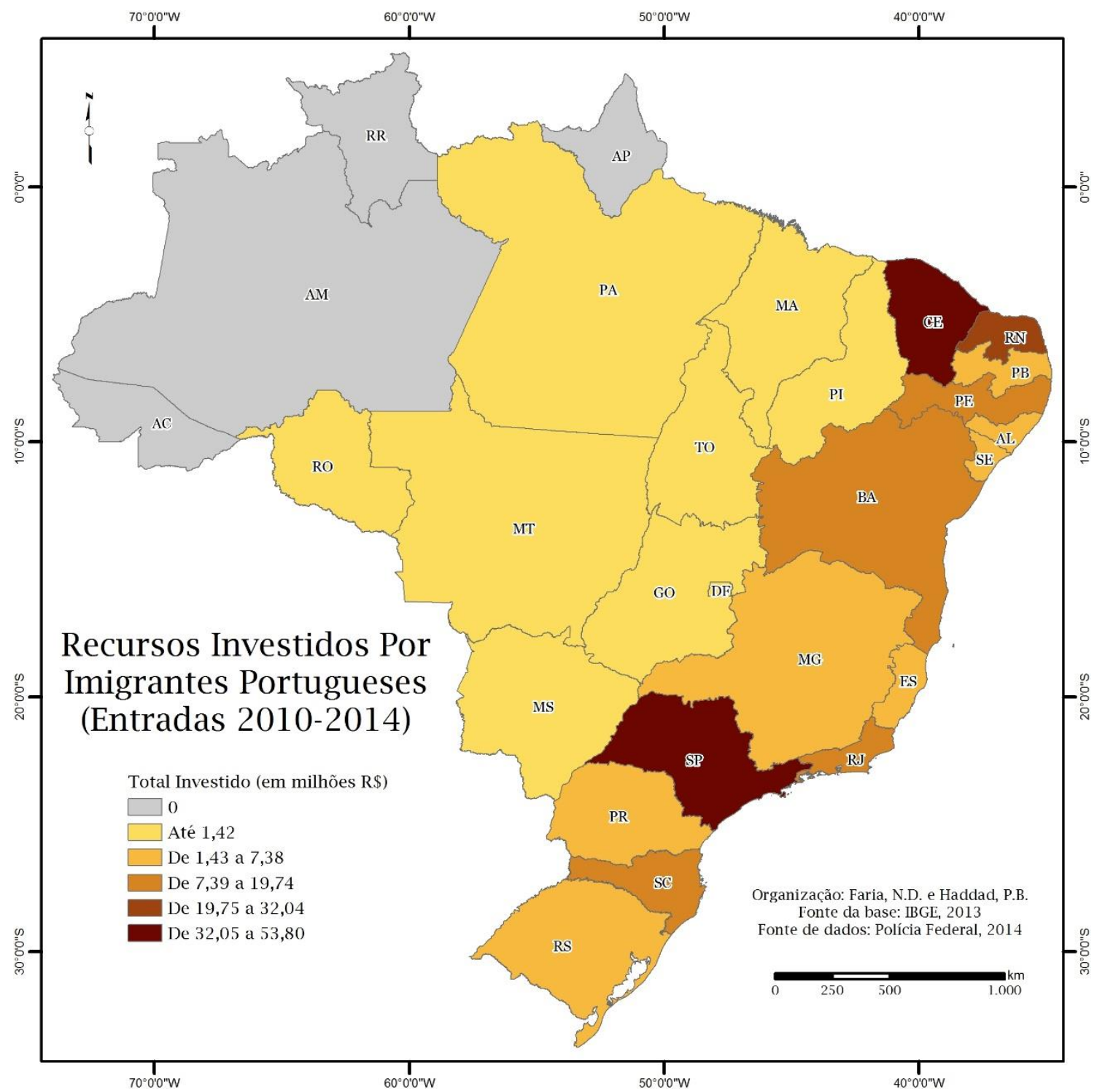

Assim como não se tem portugueses em quatro estados, os mesmos não têm investimento deste público entre os anos de estudo. Também é compatível a informação de que os Estados em variações intermediárias (investimento entre 1,42 e 7,38 milhões de reais) estão a maioria, assim como os que recebem o percentual intermediários destes portugueses (mapa 1), sendo no total de 16 Estados.

Em São Paulo e no Rio de Janeiro, devido ao maior número de entradas, as atividades económicas são mais diversas do que nos 
restantes estados, onde determinadas especialidades adquirem maior proeminência.

No caso do Ceará, o sector da construção e engenharia é de novo dominante, com $20 \%$ do total dos pedidos registados. Atividades relacionadas com a geração/ distribuição de energia elétrica somam $9 \%$, enquanto o sector imobiliário atinge $8 \%$. A fabricação de estruturas metálicas conta com 6\%, e apenas depois surge a indústria hoteleira, com $2 \%$ dos vistos atribuídos nesta região. (PESQUISA REMIGR, 2015)

\section{Considerações Finais e Sugestões}

Os dados apresentados demostram, principalmente nos mapas, que a região Norte, Centro-Oeste e Sul são as que menos recebem portugueses e seus investimentos, enquanto as regiões Sudeste e Nordeste atraem mais os portugueses investidores, mesmo sabendo que somente três estados destacamse nestas regiões: São Paulo, Rio Grande do Norte e Ceará.

Com as características econômicas destes estados, pode-se considerar que as atividades de comércio e serviços são os principais investimentos dos portugueses, chamando atenção a questão turística, uma atividade "carro-chefe" do estado do Ceará.

Considerando a importância econômica e social dos investimentos atrelado ao objetivo da $\mathrm{RN}$ no 84, sugere-se uma pesquisa in loco, observando como os empreendimentos tem contribuído para o desenvolvimento local. É preciso entender também quais as perspectivas destes negócios, ou seja, quais os planos dos portugueses investidores, nas esferas: pessoal (vínculos estabelecidos no Brasil) e profissional (expectativas do negócio). Assim conseguira-se entender como e se o objetivo da política tem sido atendido. 


\section{Referências}

BRASIL. Define a situação jurídica do estrangeiro no Brasil, cria o Conselho Nacional de Imigração: Lei 6815, de 19 de agosto de 1980. Brasília. Disponível em: http://www.planalto.gov.br/CCIVIL 03/leis/L6815.htm Acesso em: 11 de maio de 2015.

BRASIL. Resolução Normativas do Ministério do Trabalho e Emprego. Disponível em http://portal.mte.gov.br/trab estrang/resolucoes-normativas.htm Acesso em 10 de maio de 2015.

CASTELS, Stephen. Tradução de ÁGOAS, Frederico. Globalização, Transnacionalismo e Novos Fluxos Migratórios dos trabalhadores às migrações globais. Fim de Século. 2005

COENTRO, Luciana Unis. Políticas Públicas e Gestão das Migrações Internacionais no Brasil: Uma reflexão sobre os migrantes qualificados - 2011.

FERNANDES, D., M. C. Castro, e S. Knup (2013), Espanhóis e portugueses no Brasil: a migração recente, em ICMPD, Migração Brasil-Europa - A Situação dos Migrantes Brasileiros na Espanha e Portugal e de Portugueses e Espanhóis no Brasil: Aspectos Legais e Vivências, Viena, International Centre for Migration Policy Development pp. 225-270.

FERNANDES, Duval. FARIA, Natalia. A imigração recente dos portugueses para o Brasil. PEIXOTO, J., et al (orgs.) Vagas Atlânticas: Migrações em Brasil e Portugal no início do século XXI. Editora Mundos Sociais. Lisboa, 2015. pp 177192

IBGE. Instituto Brasileiro de Geografia e Estatística. Base de dados Censo 2000 e 2010. Disponível em <ibge.gov.br> Acesso em: 15 de junho de 2015.

PEIXOTO, J., e T. França (2013), $O$ acesso dos imigrantes brasileiros aos direitos em Portugal, em ICMPD, Migração Brasil-Europa - A Situação dos Migrantes Brasileiros na Espanha e Portugal e de Portugueses e Espanhóis no Brasil: Aspectos Llegais e Vivências, Viena, International Centre for Migration Policy Development, pp. 135-184.

REMIGR.Relatório preliminar. Universidade de Lisboa. 2015. mimeo 